\title{
Energy calculation model of an outgoing conveyor with application of a transfer chute with the damping plate
}

\author{
Vieroslav Molnár ${ }^{1}$, Gabriel Fedorko ${ }^{1}$, Nikoleta Husáková ${ }^{1}$, Ján Král' Jr. ${ }^{2}$, and Mirosław Ferdynus ${ }^{3}$ \\ ${ }^{1}$ Technical University of Kosice, Letna 9, 04200 Kosice, Slovak Republic \\ ${ }^{2}$ Faculty of Mechanical Engineering, Technical University of Kosice, Letna 9, 04200 Kosice, Slovak Republic \\ ${ }^{3}$ Faculty of Mechanical Engineering, Lublin University of Technology, Nadbystrzycka 36, \\ 20-616 Lublin, Poland \\ Correspondence to: Vieroslav Molnár (vieroslav.molnar@tuke.sk)
}

Received: 2 February 2016 - Revised: 22 June 2016 - Accepted: 26 July 2016 - Published: 17 August 2016

\begin{abstract}
The energy efficiency of transport systems consisting of several belt conveyors is significantly affected by re-direction. The proper sizing of several conveyor belts using deflector plates can significantly affect their efficiency. At present, there are no uniform rules (models) which specify the methodology and procedures for their design. This paper brings proposals of design of optimal parameters for energy-efficient operation of the transport system consisting of belt conveyors based on the new analytical simulation models. Recommendations for the practical application of transport systems at the transfer point have been designed according to optimization. The results are analysed in detail in three phases of shifting by means of a physical approach with the support of computing methods and simulation experiments with the transfer model. We can state that the direction and orientation of material impact have a direct influence on the conveyor's energy intensity. Thus, the inevitable condition for operation of arbitrary type of belt conveyor is to pay greater attention to the construction of the transfer model, particularly the intensity of the energy of the outgoing conveyor.
\end{abstract}

1

\section{Introduction}

Material handling is an important sector of industry (Zhang and Xia, 2011). Belt conveyors are being employed to form the most important parts of material handling systems because of their high efficiency of transportation (Alspaugh, 2004). Belt conveyors are, in most cases, the most costeffective solution for handling bulk material mass flows over short and medium conveying distances. The belt is a key component of these conveyors, and its dynamic characteristics determine the working performance to a great extent (Hou and Meng, 2008). Belt conveyors are basic intra-plant transport machines, especially in the mining industry. Due to their numerous advantages, belt conveyors are also used in other industries, such as in natural resource processing, smelting, cement and lime production, pulp and paper production, sea and river ports, civil engineering, agriculture, sugar factories, and power plants. The reason for this is that belt conveyors are simple in construction, flexible in trans- port system configuration, and versatile in use, and they also may be used to transport goods over considerable distances (Mazurkiewicz, 2008). Wensrich and Wheeler researched the method of optimization for buckling occurring on a conveyor belt (Wensrich and Wheeler, 2004). During the tumbling and movement process, motion resistance occurs, which has been described in detail (Spaans, 1999). The knowledge obtained is necessary to create the energy calculation model. The model for energy calculation of the belt conveyor is much needed for the optimization of its operating efficiency. There are two categories of models in the literature: one relying on resistance force calculation and the other on energy conversion through a compensation length. Zhang and Xia (2009) proposed a model which evolved by the interlinkage of the two categories. This model is characterized by two compensation length variables. Evidence is provided in comparative studies in terms of better accuracy and applicability.

One of the most important areas of bulk solids handling is the efficient flow of materials at transfer points within the 
system. Bulk material transfer points are found in a wide range of industries, including mining, mineral processing, chemical processing, thermal power plants, and many other areas that deal with bulk solids (Huque and McLean, 2002). Scott and Choules (1993) suggest the importance of the application of damping plates or impact boards as being the most important factor regarding their wear and tear. The simple use of damping plates and their effectiveness in terms of functionality, simple maintenance, and maximum lifetime of the transfer point is a widely discussed topic. The authors suppose that the angle under which the material impacts the damping plate can significantly affect its wear. Their article presents experiments carried out in a mining enterprise in which the transport performance of $40000 \mathrm{t}$ per day resulted in the excessive wear of damping plates. The results of the experiments indicated that modification of the damping plate shape to a certain angle of curving resulted in lower wear by impact of a high abradant. Roberts (2003) presented criteria for the selection of the most appropriate chute geometry to minimize chute wear and belt wear at the feed point. He dealt with the determination of optimum chute profiles to achieve the specified performance criteria. Benjamin et al. (2010) analysed the problem of transfer chutes as well as the design concept, maintenance, and operation of the transport system, with practical examples in broad terms. Scott (1992) analysed conveyor transfer chute design, modern concepts in belt conveying, and handling of bulk solids. Roberts (unpublished data) described how the relevant flow properties of bulk solids are measured and applied to chute design. Chute flow patterns and the application of chute flow dynamics to the determination of the most appropriate chute profiles to achieve optimum flow are described. Wensrich (2003) researched a small part of chute design, i.e. the choice of the curve or profile that the chute follows. Overall, this choice relies on minimizing wear in the chute/product and impact on the belt. Seifried et al. (2005) presented a method to evaluate the coefficient of restitution for multiple impacts between material bodies.

The most widespread applied method examining interaction of material flow particles during the re-direction by the help of transfer chutes is the discrete element method (DEM), and tools are developed according to this simulation. Simulation experiments on the basis of this method are presented by most of the authors in order to optimize and design elements of transfer chutes. Bertrand et al. (2005) discussed the current state of the art in the modelling of granular flows in mixing processes; the authors then focus on the DEM, which has recently proven worthy of interest for the mixing of granular materials. There are numerous methods available with which to analyse particle flow through a conveyor transfer, including continuum-based analytical methods, the DEM, and experimental analysis. Research is presented by Gröger and Katterfeld (2007), Kessler and Prenner (2009), Grima and Wypych $(2010,2011)$, and Dewicki (2003) regarding the interaction caused by the contact of particles of material flow during impacts on the walls of transfer chutes or damping plates. Results of simulation experiments indicate that the shape, material, and construction of transfer chutes affect the structure and deformation of spherical particles of the material as a result of their mutual contact. Minkin (2012) reports about the application of the DEM for an analysis of the "rock box" transfer stations, which are widely used in the mining industry. David and Kruses described input parameters obtained by simulation with current application of the DEM (for example, static or dynamic loads of material, material density, adhesion and cohesion of the particles of material, restitution coefficient, viscosity). Di Renzo and Di Maio (2004) examined the evolution of the forces, velocities, and displacements during the collision, emphasizing the importance of correctly accounting for non-linearity in the contact model and micro-slip effects. Chandramohan and Powell (2005) researched preliminary numerical simulations using the standard viscous damping model are performed using the DEM and a comparison between experimental and numerical results. Bierwisch et al. (2009) investigated the rapid granular flow from a moving container and angle of repose formation by means of numerical simulations using the DEM and experiments. Mcllvenna and Mossad (2003) reported an investigation into a continuum model based on kinetic theory as an alternative to the DEM for basic transfer chute analysis. Software for the fluent analysis has been used to perform two-dimensional modelling of chutes, and the result is compared to traditional design methods. Hastie and Wypych (2010) detailed their findings regarding three methods for granular cohesionless materials. The experimental investigations were performed on a conveyor transfer research facility located at the University of Wollongong, using high-speed video to capture the flow and subsequently analysing this with Image Pro Plus. Donohue et al. (2010) modelled granular flow through a constant radius chute using computational fluid dynamics (CFD) in which a multiphase simulation is considered. This approach provides valuable information about the flow of dust, and the results are confirmed by experimental observations. Jensen et al. (1999) presented an enhanced DEM for the numerical modelling of particulate media. This method models a particle of general shape by combining several smaller particles of simpler shape, such as a circle, into clusters that act as a single larger particle. The clusters more accurately model the geometrydependent behaviour of the particles, such as particle interlock and resistance to rolling. The method is implemented within the framework of an existing DEM program without the introduction of new contact or force algorithms. Zhang and Xia (2011) researched the model-based optimization approach to improve the efficiency of belt conveyors at the operational level. 


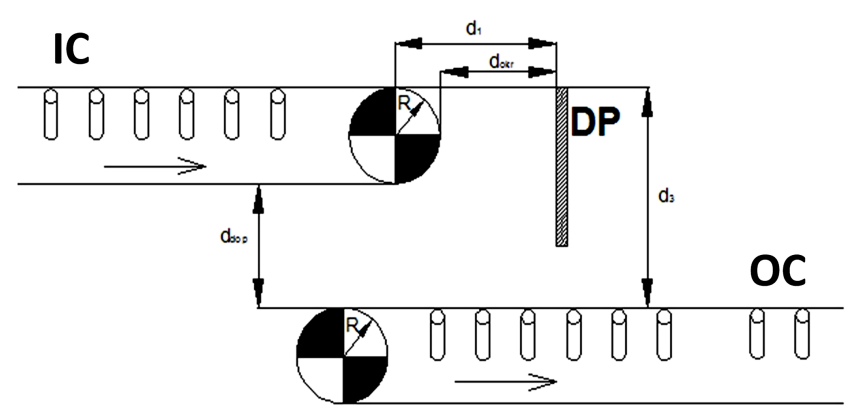

Figure 1. Simplified model of material re-direction. DP - damping plate; IC - incoming conveyor; OC - outgoing conveyor.

\section{Energy calculation model}

The energy calculation model of the outgoing conveyor with application of a transfer chute with the damping plate was determined by a basic model of transport system consisting of

1. two belt conveyors with the belt (transbelt) with a onepulley drive suitable for transport of granular and bulk material,

2. a firmly and perpendicularly gripped damping plate of metal material aligned to the $x$ axis of the incoming conveyor belt (Fig. 1).

When we examine kinematic and dynamic effects on the basis of theoretical analysis, we consider the basic model of the conveying systems with re-direction of one particle of granular material, not with material flow of particles, or pieces. Incoming and outgoing conveyors have the same direction and orientation of movement, and the drive pulley has the same diameter.

\subsection{Input parameters of the basic model of re-direction}

For the calculation of kinematic and dynamic effects of the basic re-direction model, the following technical and selected parameters have been used:

1. speed of conveyor belts $v_{0}$,

2. radius of pulleys $R$ for rubber-textile conveyor belts,

3. horizontal distance of the damping plate from the incoming conveyor $d_{\mathrm{okr}}$

4. vertical distance among conveyors $d_{3}$,

5. mass of particles for granular bulk material $m$,

6. coefficient of restitution $\varepsilon$.

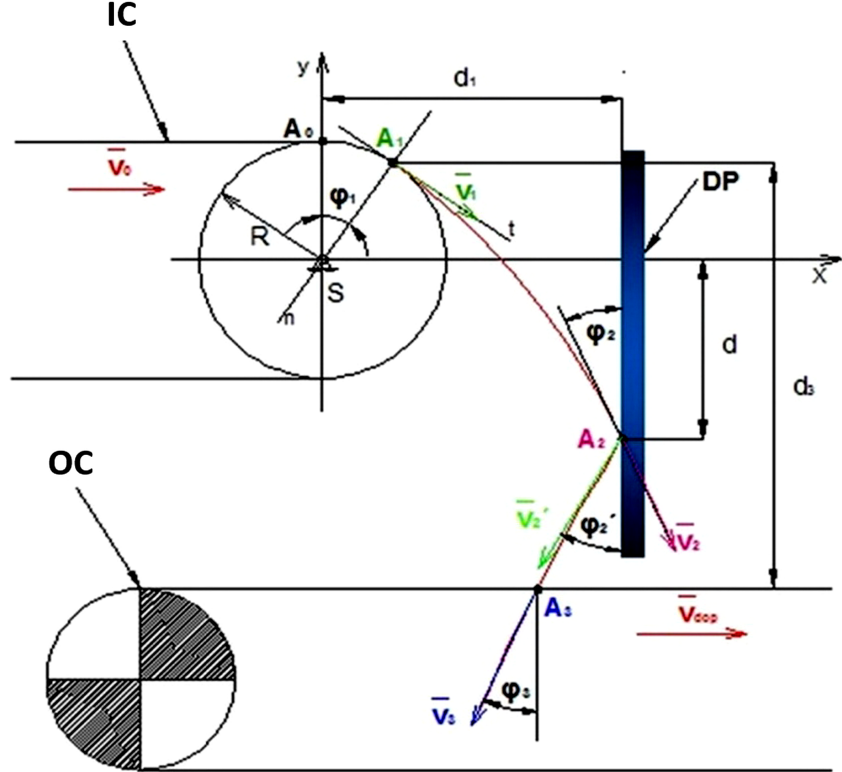

Figure 2. Trajectory of material particle movement during three phases. DP - damping plate; IC - incoming conveyor; OC - outgoing conveyor.

\subsection{The goal of the kinematic and dynamic analysis}

The analysis carried out was intended to research the effect of mechanical energy of a material particle on the energy demand of an outgoing conveyor during three phases (Fig. 2).

The first phase was aimed at the separation of the particle from the drive pulley of the incoming conveyor (IC) at point $\mathrm{A}_{1}$ and the movement of the free material particle for impact on the damping plate (DP) from point $\mathrm{A}_{1}$ to point $\mathrm{A}_{2}$. It was assumed at the interval of movement $\mathrm{A}_{0} \mathrm{~A}_{1}$ that the adhesion among bulk material and conveyor belt is such that there is no relative movement among the particle of bulk material and conveyor belt; therefore,

$\overline{v_{1}}=\overline{v_{0}}$,

where $\overline{v_{0}}$ is the speed of the conveyor belt $\left[\mathrm{m} \mathrm{s}^{-1}\right]$ and $\overline{v_{1}}$ is the speed of the particle for bulk material $\left[\mathrm{m} \mathrm{s}^{-1}\right]$.

In the interval $\mathrm{A}_{1} \mathrm{~A}_{2}$, the trajectory of the material particle (theoretical depiction of movement kinematics) is at an angle with input values $v_{1}, \varphi_{1}$. During this movement, if we neglect air resistance, the mass point is affected only by the force of gravity $\bar{G}$ (Fig. 3).

The second phase focuses on the material particle's impact on the DP and reflection $\rightarrow A_{2}$. At the moment of the material particle meeting with a fixed damping plate, the phenomenon of impact, in terms of mechanics, occurs. In the moment of impact on the mass point, the impact force $\overline{F_{R}}$ occurs. The impact force $\overline{F_{R}}$ is the result of surface load which occurs on the contact surface after the impact of the material particle with the damping plate (for our case, point $A_{2}$ ). 


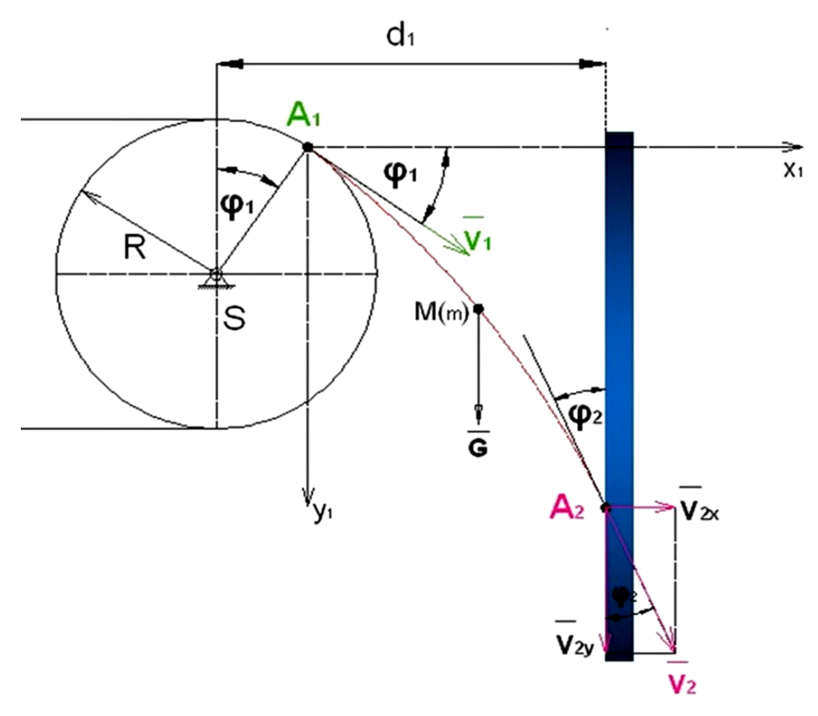

Figure 3. Movement of material particle from point A1 to point of impact A2.

Its carrier is a normal line which faces in a perpendicular direction towards the damping plate (Fig. 4). Resulting from Fig. 4, the change in material particle momentum is only at the direction of the $x$ axis, so the material particle has an imperfect elastic central impact. Because the position of the damping plate is at rest, based on the theory of direct central impact, their common speed at the end of both phases is zero. In the direction of the $y$ axis, the material particle performs an imperfectly elastic direct central stroke and the position of damping plate is unchanged. The velocity component of the material particle in the direction of the $y$ axis stays unchanged.

Furthermore, the dynamics of the impact are affected by different elastic material properties of the mass point and damping plate, the effect of which is expressed as the coefficient of restitution $\varepsilon$. To calculate the input parameters of the model of rebound, the values for the coefficient of restitution are selected in the range $0<\varepsilon<1$.

The third phase describes the impact of the material particle on the outgoing conveyor $(\mathrm{OC}) \rightarrow \mathrm{A}_{3}$. Figure 5 presents the movement of the mass point from position $\mathrm{A}_{2}$ to position $\mathrm{A}_{3}$ as well as the resolution of the velocity components at the point of the material particle's impact on the OC as a projection at an angle. To calculate the distance of the impact of material particle $x_{3}$ on the $\mathrm{OC}$ from the damping plate, value $d_{2}$ was used as defined in the equation in Fig. 5.

These phases of shifting were analysed as three separate tasks in which material particle movement analysis was oriented to the determination of input values with the following defined equations:

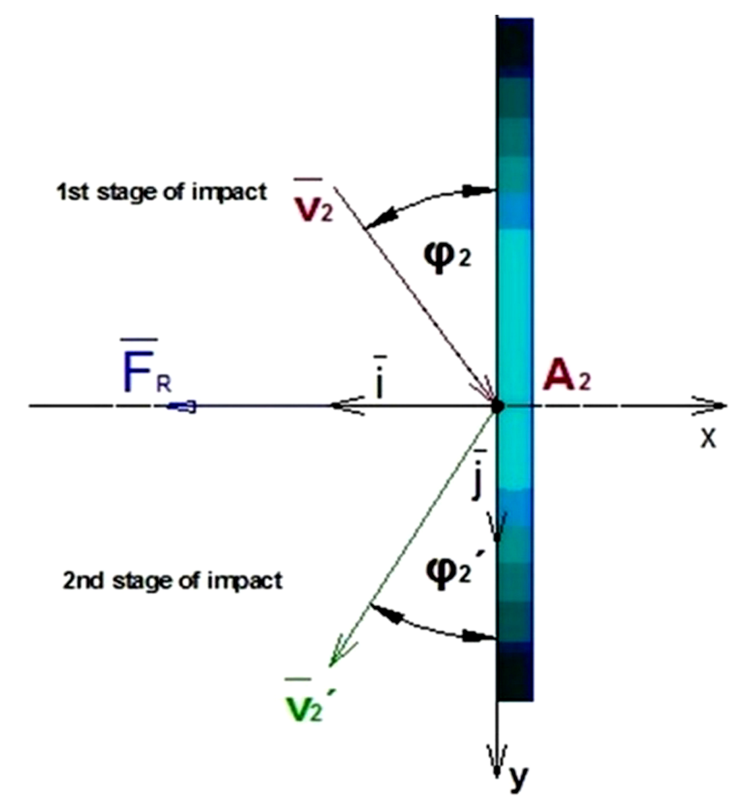

Figure 4. Impact force at the moment of the material particle impacting the damping plate and immediately after the impact.

- The angle of bulk material particle separation from the drive pulley of IC $\varphi_{1}$ according to CEMA (2007):

$$
\cos \phi_{1}=\frac{v_{1}^{2}}{g \cdot R} \Rightarrow \operatorname{arcos} \phi_{1}=\frac{v_{1}^{2}}{g \cdot R}\left[^{\circ}\right] \text {. }
$$

- Coordinates of bulk material particle impact $\left[x_{2}, y_{2}\right]$ at time $t_{2}$ :

$$
\begin{aligned}
& x_{2}=v_{1} \cdot t_{2} \cdot \cos \phi_{1}[\mathrm{~m}], \\
& y_{2}=g \cdot \frac{t^{2}}{2}+v_{1} \cdot t_{2} \cdot \sin \phi_{1}[\mathrm{~m}], \\
& t_{2}=\frac{d_{1}-R \cdot \sin \phi_{1}}{v_{1} \cdot \cos \phi_{1}}[\mathrm{~s}] .
\end{aligned}
$$

- The size of bulk material velocity at the time of impact on the DP $v_{2}$ :

$$
v_{2}=\sqrt{v_{2 x}^{2}+v_{2 y}^{2}}\left[\mathrm{~ms}^{-1}\right] \text {. }
$$

- The angle of velocity direction $v_{2}$, or the angle $\varphi_{2}$, under which the bulk material particle impacts the DP:

$$
\tan \phi_{2}=\frac{v_{2 x}}{v_{2 y}} \Rightarrow \phi_{2}=\arctan \frac{v_{2 x}}{v_{2 y}}\left[{ }^{\circ}\right]
$$

- The angle of bulk material reflection from the DP $\varphi_{2^{\prime}}$ :

$$
\tan \phi_{2^{\prime}}=\varepsilon \cdot \operatorname{tg} \phi_{2} \Rightarrow \phi_{2^{\prime}}=\arctan \left(\varepsilon \cdot \tan \phi_{2}\right)\left[{ }^{\circ}\right] .
$$

- The size of bulk material velocity $v_{2^{\prime}}$ after reflection from DP:

$$
v_{2}^{\prime}=v_{2} \sqrt{\sin ^{2} \phi_{2}+\varepsilon^{2} \cdot \cos ^{2} \phi_{2}}\left[\mathrm{~ms} \mathrm{~s}^{-1}\right] .
$$




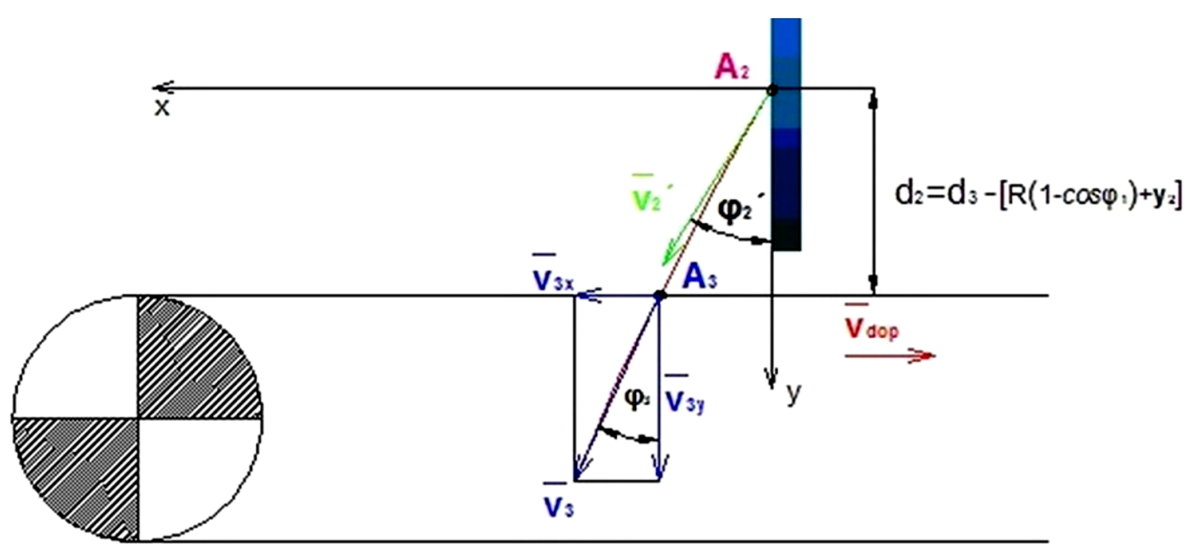

Figure 5. Decomposition of velocity components at the point of the material particle's impact on the OC.

- Coordinates of bulk material particle impact $\left[x_{3}, y_{3}\right]$ at time $t_{3}$ :

$x_{3}=v_{2^{\prime}} \cdot t_{3} \cdot \sin \phi_{2^{\prime}}[\mathrm{m}]$,

$y_{3}=g \cdot \frac{t_{3}^{2}}{2}+v_{2^{\prime}} \cdot t_{3} \cdot \cos \phi_{2^{\prime}}[\mathrm{m}]$,

$t_{3}=\frac{-b \pm \sqrt{b^{2}-4 \cdot a \cdot c}}{2 a}[\mathrm{~s}]$,

where $\quad a=\frac{g}{2}, \quad b=v_{2^{\prime}} \cdot \cos \phi_{2^{\prime}}, \quad$ and $\quad c=$ $\left[R \cdot\left(1-\cos \phi_{1}\right)+y_{2}\right]-d_{3}$.

- The size of velocity of bulk material particle at the time of impact on the belt of OC $v_{3}$ :

$v_{3}=\sqrt{v_{3 x}^{2}+v_{3 y}^{2}}\left[\mathrm{~m} \mathrm{~s}^{-1}\right]$.

- The change in kinetic energy $E_{\mathrm{k}}$ of the material particle after the impact on the OC:

$\Delta E_{\mathrm{k}}=\frac{1}{2} \cdot m \cdot\left(v_{3 x}^{2}+v_{\mathrm{dop}}^{2}\right)[J]$.

- Instantaneous engine power of the outgoing conveyor $P$ :

$P=\frac{m}{2 \cdot t} \cdot\left(v_{3 x}^{2}+v_{\mathrm{dop}}^{2}\right)[W]$.

The angle under which the material impacts the damping plate markedly affects its wear, as also mentioned in Scott and Choules (1993). The correct setup of the transfer chute minimizes wear in the chute/product and impact on the belt of the outgoing conveyor.

\subsection{Comparison of energy calculation model for the velocity $v_{0}=\left(2 \mathrm{~ms}^{-1} ; 4 \mathrm{~ms}^{-1}\right)$}

The energy calculation model of the outgoing conveyor compares the change in kinetic energy of a material particle after hitting the $\mathrm{OC}$ with dependence on the radius of a drive pulley by doubling of the conveyor velocity. The change in conveyor velocity has an equally strong influence on the perpendicular and vertical distance of the material particle's impact on the damping plate and $\mathrm{OC}$ as well as the change in the material particle's velocity during the three phases of shifting, with perceptible differences in the values of impact angles, rebounds, and impacts.

For the calculation of the investigated kinematic and dynamic effects by interaction of material with damping plate, or material with the conveyor belt, the following technical and selected parameters of the transfer model were used:

1. normalized velocities of conveyor belts;

2. diameters of pulleys for rubber-textile conveyor belts with allowable stress in tensile force of up to $30 \%$ and with a polyamide insert according the manufacturer's recommendations;

3. horizontal distance of the damping plate from the incoming conveyor $d_{1}$, which is equal to the sum of the values of the interval $d_{\mathrm{okr}}=<0.5 \mathrm{~m} \div 1 \mathrm{~m}>$ and values of the radius of the drive pulley $R$;

4. consistently chosen vertical distance among conveyors $d_{\text {dop }}$, with the distance $d_{3}$ determined as

$d_{3}=R \cdot\left(1-\cos \phi_{1}\right)+y_{2}+d_{2}[\mathrm{~m}]$,

where $R$ is the radius of the drive pulley of IC [m], $\phi_{1}$ is the angle of material particle separation from the drive pulley $\left[{ }^{\circ}\right]$, and $y_{2}$ is the $y$ coordinate of the material particle from the place of separation on the upwardcarrying pulley to the place of impact on the damping plate $[\mathrm{m}]$;

5. weight of bulk material particle $m=7.95 \mathrm{~g}-8 \mathrm{~g}$;

6. coefficient of restitution $\varepsilon=0.5$. 


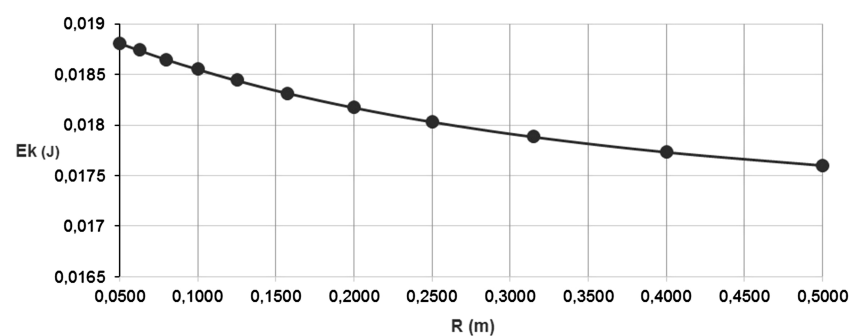

Figure 6. Dependence of kinetic energy $E_{\mathrm{k}}$ and radius $R$ of the drive pulley at velocity $v_{0}=2 \mathrm{~m} \mathrm{~s}^{-1}$.

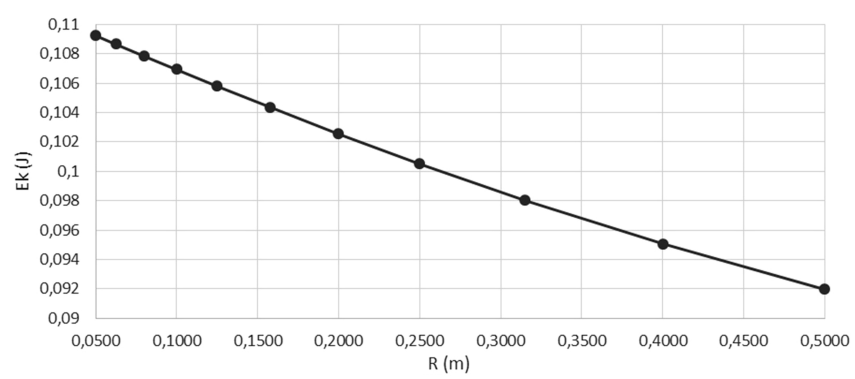

Figure 7. Dependence of kinetic energy $E_{\mathrm{k}}$ and radius $R$ of the drive pulley at velocity $v_{0}=4 \mathrm{~m} \mathrm{~s}^{-1}$.

Figures 6 and 7 present a comparison of kinetic energy changes for the material particle after impact on the OC. These figures indicate that the increasing radius of the IC results in a decrease in the velocity component for material particle $v_{3 x}$, thereby also causing a decrease in the kinetic energy of material particle $E_{\mathrm{k}}$ after the impact.

Figure 7 presents the increase in the kinetic energy of material particle $E_{\mathrm{k}}$ after the impact by double velocity $v_{0}$.

In the first phase of re-direction, the rate of distance $x_{2}$ at the point of the material particle impacting the DP depends on the point of separation of material particle from the drive pulley of IC, or the angle $\varphi_{1}$. With regard to the distance of DP $d_{1}$, the distance $x_{2}$ can not be more than $d_{1}$. When the angle $\varphi_{1}=0^{\circ}, x_{2}=d_{1}$. The distance $y_{2}$ gradually decreases with velocity $v_{1}$ increasing, and it increases with regard to the larger radius of the drive pulley $R$. This is also affected, besides the velocity $v_{1}$ and radius $R$, by the horizontal distance of the DP $d_{\mathrm{okr}}$; therefore, for practical reasons, a smaller distance $d_{\mathrm{okr}}$ between IC and DP is convenient.

In the second phase of re-direction, distance $x_{3}$ increases with the change in velocity $v_{1}$; however, it decreases with the increase in radius of the drive pulley $R$. With regard to the vertical distance from the point of the material particle impacting the DP up to the point where the material particle lands on the OC $d_{2}=0.5 \mathrm{~m}$, the distance $y_{3}$ stays constant for both velocities $v_{1}$ and radiuses of drive pulleys $R$, i.e. $d_{2}=y_{2}$.

Table 1 presents the comparison of the material particle distance at the point of impact on the DP (coordinates at point

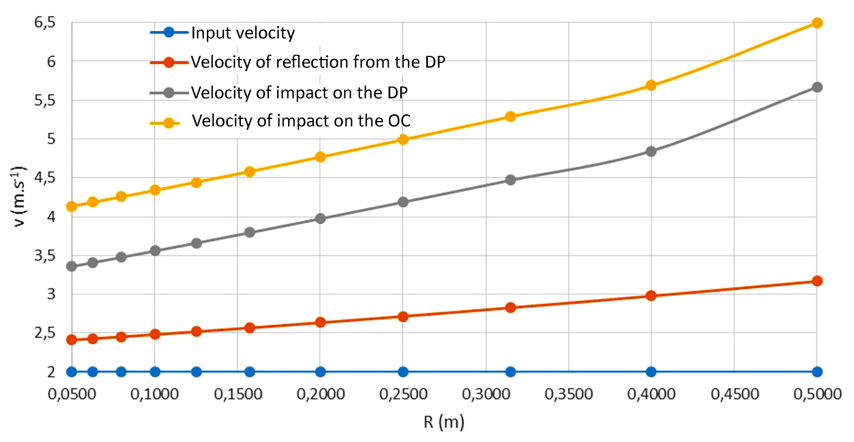

Figure 8. Graph of the velocity change for the material particle at $v_{1}=2 \mathrm{~m} \mathrm{~s}^{-1}$.

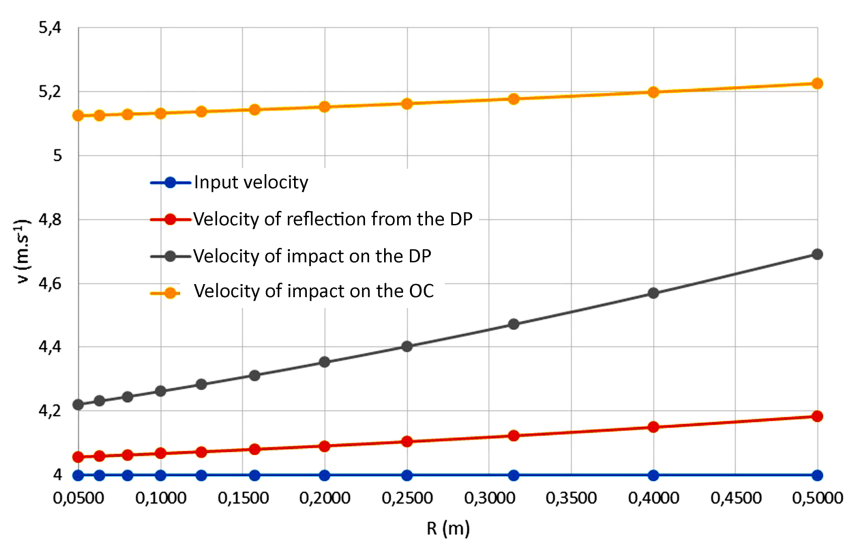

Figure 9. Graph of the velocity change for the material particle at $v_{1}=4 \mathrm{~m} \mathrm{~s}^{-1}$.

$\mathrm{A}_{2}$ ) and at the point of impact on the OC (coordinates at point $\mathrm{A}_{3}$ ).

In the first phase of re-direction with regard to time $t_{2}$, which with an increase in the velocity $v_{1}$ decreases, the magnitude of velocity component $v_{2 x}$ ncreases and the magnitude of velocity component $v_{2 y}$ decreases. In the case $\varphi_{1}=0^{\circ}$, the velocity component $v_{2 x}$ is, as a result of impact on the DP, equal to the velocity $v_{1}$. In the second phase, after it bouncing off the DP, the material particle reaches the velocity $v_{2^{\prime}}$, which, compared with the impact velocity on the DP, is always smaller. This fact arises by the damping of the impact of the material particle by the DP.

By increasing the radius of a drive pulley $R$, the velocity $v_{2}$ increases. The size of velocity component $v_{3 x}$ for the material particle increases in the third phase of shifting after the impact on the OC with increasing velocity $v_{1}$. With a larger radius of the drive pulley $R$, the size of velocity component $v_{3 x}$ for the material particle decreases, which leads to a decrease in the kinetic energy $E_{\mathrm{k}}$ of the material particle after the impact.

Figures 8 and 9 present the comparison of material particle velocity changes during three phases of shifting for both velocities. 
Table 1. Evaluation of coordinates $\left[x_{2}, y_{2}\right]$ and $\left[x_{3}, y_{3}\right]$ for velocities $v_{1}$.

\begin{tabular}{lcccccccc}
\hline \multirow{2}{*}{ Radius of carrying-up drum } & \multicolumn{3}{c}{$x$ and $y$ coordinate at point $\mathrm{A}_{2}$} & \multicolumn{3}{c}{$x$ and $y$ coordinate at point $\mathrm{A}_{3}$} \\
\cline { 2 - 10 } & \multicolumn{2}{c}{$v_{0}=2 \mathrm{~m} \mathrm{~s}^{-1}$} & $v_{0}=4 \mathrm{~m} \mathrm{~s}^{-1}$ & $v_{0}=2 \mathrm{~m} \mathrm{~s}^{-1}$ & $v_{0}=4 \mathrm{~m} \mathrm{~s}^{-1}$ \\
\hline$R[m]$ & $x_{2}\left(t_{2}\right)$ & $y_{2}\left(t_{2}\right)$ & $x_{2}\left(t_{2}\right)$ & $y_{2}\left(t_{2}\right)$ & $x_{3}\left(t_{3}\right)$ & $y_{3}\left(t_{3}\right)$ & $x_{3}\left(t_{3}\right)$ & $y_{3}\left(t_{3}\right)$ \\
\hline 0.0500 & 0.550 & 0.371 & 0.550 & 0.093 & 0.137 & 0.5 & 0.548 & 0.5 \\
0.0625 & 0.563 & 0.388 & 0.563 & 0.097 & 0.134 & 0.5 & 0.539 & 0.5 \\
0.0800 & 0.580 & 0.413 & 0.580 & 0.103 & 0.131 & 0.5 & 0.528 & 0.5 \\
0.1000 & 0.600 & 0.441 & 0.600 & 0.110 & 0.127 & 0.5 & 0.515 & 0.5 \\
0.1250 & 0.625 & 0.479 & 0.625 & 0.120 & 0.123 & 0.5 & 0.500 & 0.5 \\
0.1575 & 0.658 & 0.530 & 0.658 & 0.133 & 0.118 & 0.5 & 0.481 & 0.5 \\
0.2000 & 0.700 & 0.601 & 0.700 & 0.150 & 0.112 & 0.5 & 0.458 & 0.5 \\
0.2500 & 0.750 & 0.690 & 0.750 & 0.172 & 0.106 & 0.5 & 0.434 & 0.5 \\
0.3150 & 0.815 & 0.815 & 0.815 & 0.204 & 0.099 & 0.5 & 0.405 & 0.5 \\
0.4000 & 0.900 & 0.993 & 0.900 & 0.248 & 0.092 & 0.5 & 0.373 & 0.5 \\
0.5000 & 0.711 & 1.435 & 1.000 & 0.307 & 0.062 & 0.5 & 0.341 & 0.5 \\
\hline
\end{tabular}

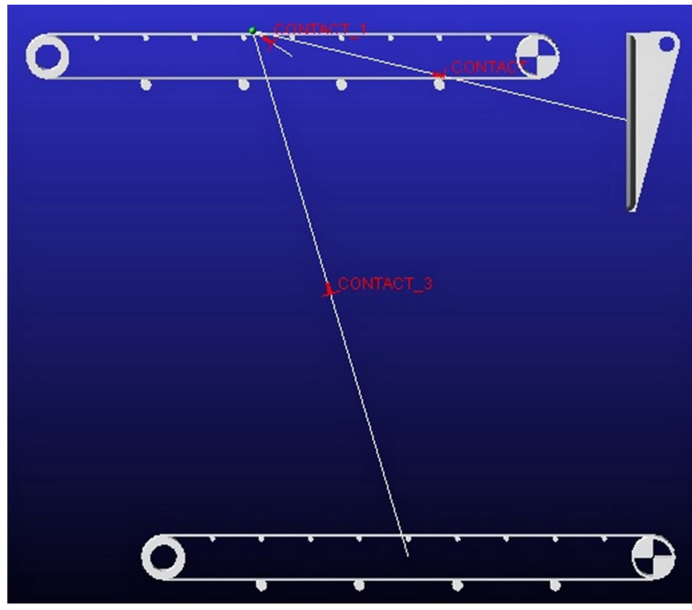

Figure 10. View of re-direction model in the ADAMS environment.

3 Simulation experiments with energy calculation model of transfer with perpendicular and inclined damping plate for velocities $v_{0}=\left(2 \mathrm{~m} \mathrm{~s}^{-1} ; 4 \mathrm{~m} \mathrm{~s}^{-1}\right)$

The aim of experimenting with the transfer model was the verification of the trajectory of material particle movement in accordance with analytical calculation. We selected the distance of DP from IC $d_{\mathrm{okr}}=0.5 \mathrm{~m}$ and the distance between the IC and OC as input parameters. The starting point for determination of the height of the damping plate was the total height of shifting $d_{3}$.

By reason of the absence of the type of material (sand) taken into account in comparison of the energy model, it was associate the type of material - steel for material particle from offered possibilities of the program.

As an alternative, we chose fixed-level supports (incoming belt), along which the material particle moves with an associated speed $v_{1}$.
Table 2 presents constructive parameters of components for the transfer model with associated input values.

With the use of construction parameters, a simplified transfer model was created, consisting of two fixed and rigid horizontal trays and the DP placed perpendicularly towards the trays and material particle, or a steel ball (Fig. 10).

For assurance of the material particle's impact on the DP and its impact with the bottom horizontal support, we defined these contacts in the transfer model:

1. contact of material particle with horizontal support as IC,

2. contact of material particle with the DP and the coefficient of restitution 0.5 ,

3. contact of material particle with the horizontal support as OC.

$v_{1}$ velocity was assigned for the material particle, and the change in velocity during the simulation is affected by gravitational acceleration $g=9.81 \mathrm{~m} \mathrm{~s}^{-2}$.

For the purpose of verification of the model functionality for the designed and created transfer model, a simulation was realized in which the material particle impacted on the DP and fell out on the bottom horizontal support.

\subsection{Perpendicular damping plate}

Figure 11 shows how the material particle, after leaving the IC, changes its trajectory of movement with dependence on changes in input velocity $v_{1}$.

The general evaluation of the analytical calculation of results showing the values of coordinates $\left[x_{2}, y_{2}\right]$ of the material particle at the moment of its impact on the DP for standardized velocities $v_{1}$ demonstrated the consistence after the simulation experiments were carried out. 

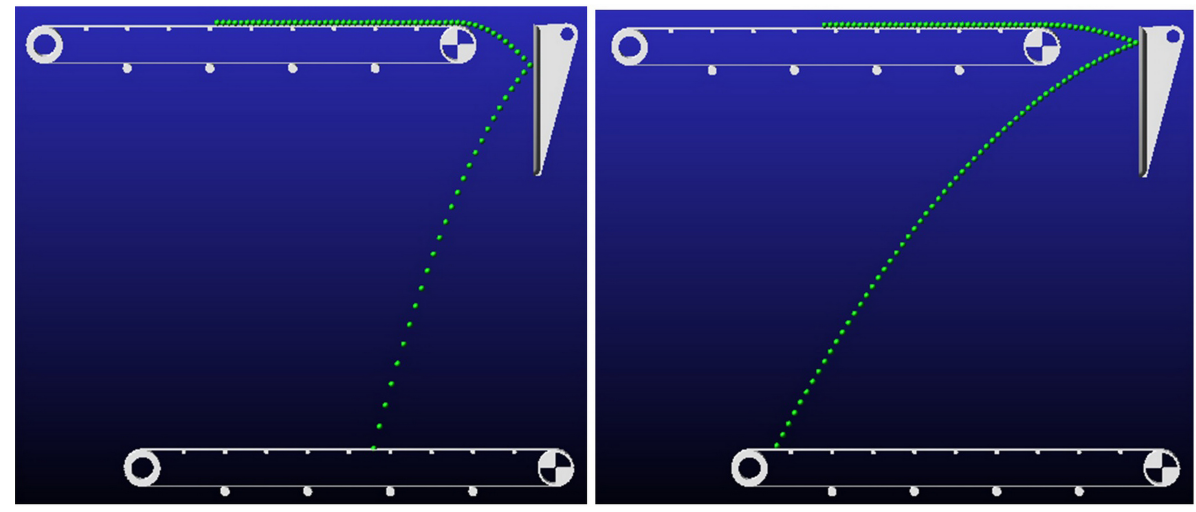

Figure 11. Trajectory of the material particle's movement at $v_{1}=2 \mathrm{~m} \mathrm{~s}^{-1}$ (left), $v_{1}=4 \mathrm{~m} \mathrm{~s}^{-1}$ (right).

Table 2. Parameters of the re-direction model in the workbench of the program ADAMS.

\begin{tabular}{lllllllll}
\hline & \multicolumn{1}{c}{ Parameters of re-direction model } \\
\cline { 2 - 9 } Title & $\begin{array}{l}\text { Length } \\
{[\mathrm{mm}]}\end{array}$ & $\begin{array}{l}\text { Height } \\
{[\mathrm{mm}]}\end{array}$ & $\begin{array}{l}\text { Width } \\
{[\mathrm{mm}]}\end{array}$ & $\begin{array}{l}\text { Radius } \\
{[\mathrm{mm}]}\end{array}$ & $\begin{array}{l}\text { Weight } \\
{[\mathrm{kg}]}\end{array}$ & $\begin{array}{l}\text { Material } \\
\text { density }\left[\mathrm{kg} \mathrm{mm}^{-3}\right]\end{array}$ & $\begin{array}{l}\text { Modulus of } \\
\left.\mathrm{elasticity}^{[\mathrm{Nmm}} \mathrm{mm}^{-2}\right]\end{array}$ & $\begin{array}{l}\text { Poisson } \\
\text { number }[-]\end{array}$ \\
\hline Horizontal support (IC) & 1000 & 50 & 400 & $\mathrm{x}$ & $\mathrm{x}$ & $\mathrm{x}$ & $\mathrm{x}$ & $\mathrm{x}$ \\
Horizontal support (OC) & 2000 & 50 & 400 & $\mathrm{x}$ & $\mathrm{x}$ & $\mathrm{x}$ & $\mathrm{x}$ & $\mathrm{x}$ \\
Damping plate & 50 & 2520 & 500 & $\mathrm{x}$ & $\mathrm{x}$ & $\mathrm{x}$ & $\mathrm{x}$ \\
Material particle & $\mathrm{x}$ & $\mathrm{x}$ & $\mathrm{x}$ & 20 & 0.26 & $7.80 .10^{-6}$ & $2.07 .10^{5}$ & 0.29 \\
\hline
\end{tabular}

With the increase in velocity $v_{1}$, the material particle, after its separation from IC, gradually achieves a lower vertical distance $y_{2}$ at the moment of its impact on the DP. Due to the absence of a drive pulley in the simulated model, the distance $x_{2}$ was the same as in the analytical calculation for all velocities $v_{1}$, with the angle $\varphi_{1}=0^{\circ}$.

It results from Fig. 11 that, with increasing velocity $v_{1}$, the angle $\varphi_{2}$ increases. This fact is evidenced by the results obtained by analytical calculation.

With gradually increasing velocity $v_{1}$, the kinetic energy of the moving material particle increases; Table 3 presents its values at the moment of the impact on the DP and the impact on horizontal support OC. By calculation of kinetic energy, the coefficient of restitution was reflected as $\varepsilon=0.5$.

\subsection{Inclined damping plate}

With regard to the transfer model with the material particle velocity $v_{1}=2 \mathrm{~m} \mathrm{~s}^{-1}$, the simulation created the impact of material particle on the DP with the angle of inclination $\alpha=20^{\circ}$ and also $\alpha=40^{\circ}$. In both cases, the material particle continued in the movement oriented at the positive direction of the $x$ axis, as shown in Fig. 12. To achieve the effect of lower energy intensity in the case of the belt conveyor with the same direction and orientation of movement, the better alternative is the situation displayed on the right in Fig. 12.

The distance from the horizontal support IC defined as DP $0.1 \mathrm{~m}$ at the inclination angle $\alpha \leq 20^{\circ}$ for the velocity $v_{1}=1 \mathrm{~m} \mathrm{~s}^{-1}$ indicated a sharp shock and bounce from the DP, after which the material particle continued in the negative direction and orientation of the $x$ axis. At the angle of inclination $\alpha=40^{\circ}$ of the DP and the velocity of material particles $v_{1}=2 \mathrm{~m} \mathrm{~s}^{-1}$, the particles featured the identical direction of impact movement on horizontal support OC (Fig. 12).

The effect of the energy efficiency of the belt conveyor is increased if, with this velocity $v_{1}$, we choose a larger angle of the DP, for example $\alpha=60^{\circ}$, by which the material particle almost "matches" the position of inclination of the DP and moves in a positive direction and orientation of the $x$ axis (Fig. 13). With a larger angle of inclination of the DP, the material particle does not impact on the DP. Therefore, if it is applied only for purpose of the direction of transported material, it is possible to exclude the DP.

From simulation experiments of energy calculation model, it results that, with higher velocity $v_{1}$ and angle of inclination of DP, we get the effect of smaller resistance of OC as a result of material particle impact in the positive direction and orientation of the $x$ axis.

\section{Design of recommendations for the practical application of transport systems at the point of rebound}

By changing selected input parameters it was found that the energy intensity and instantaneous engine power of OC are 
Table 3. Values of the kinetic energy for selected velocities $\mathrm{v}_{1}$.

\begin{tabular}{lll}
\hline Velocity of the material particle & Kinetic energy at impact $E_{k 1}[\mathrm{Nmm}]$ & Kinetic energy at impact $E_{k 2}[\mathrm{Nmm}]$ \\
\hline$v_{1}=2 \mathrm{~m} \mathrm{~s}^{-1}$ & 17675.36 & 19997.61 \\
$v_{1}=4 \mathrm{~m} \mathrm{~s}^{-1}$ & 34846.60 & 93569.14 \\
\hline
\end{tabular}
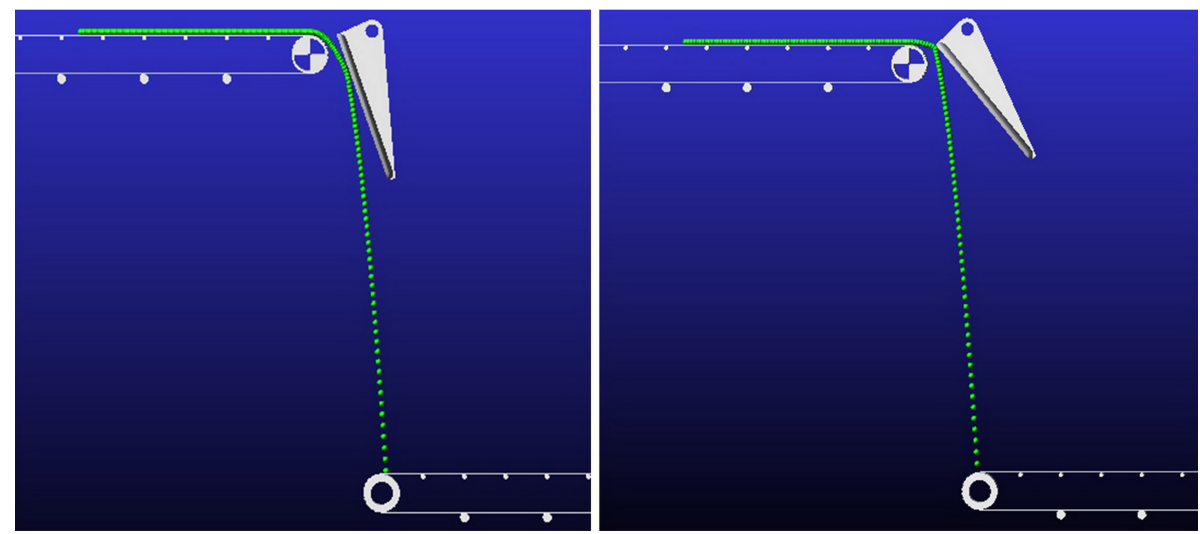

Figure 12. Trajectory of the material particle movement at $v_{1}=1 \mathrm{~m} \mathrm{~s}^{-1}, \alpha=20^{\circ}$ (left), $v_{1}=2 \mathrm{~m} \mathrm{~s}^{-1}, \alpha=40^{\circ}$ (right).

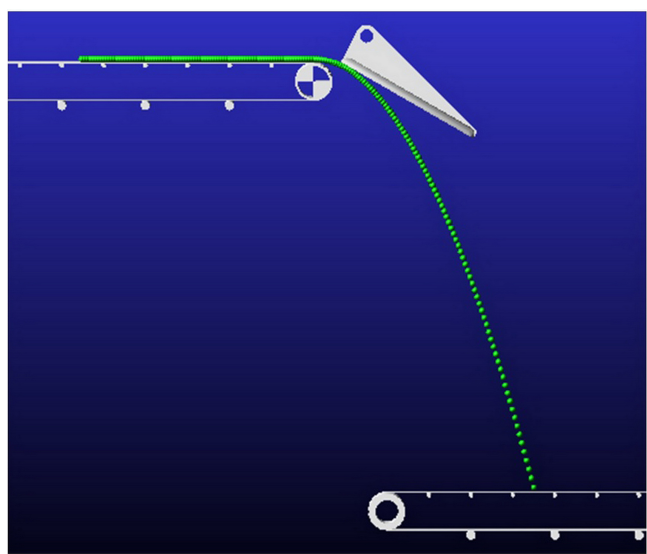

Figure 13. Trajectory of the material particle movement at $v_{1} \mathrm{~ms}^{-1}, \alpha=60^{\circ}$.

affected by the horizontal distance of the DP from the IC $d_{1}$ and the coefficient of restitution $\varepsilon$. With $0<\varepsilon \leq 0.5$, we determined the decrease in kinetic energy of material particle $E_{\mathrm{k}}$ after the impact, and with $0.5<\varepsilon<1$ the increase in $E_{\mathrm{k}}$. Because the value of the coefficient of restitution depends on the mathematical and physical properties of transported material and the character of the DP material, operators of conveying systems can not affect the coefficient of restitution by constructive change in the place of rebound. Therefore, optimization of $d_{1}$ was only considered for the value of the coefficient of restitution $\varepsilon=0.5$.

The vertical distance from the point of particle impact on the DP to the point at which the material particle falls onto the OC $d_{2}$, the magnitude of the kinetic energy of material particle $E_{\mathrm{k}}$ after the impact is not affected. This distance affects the velocity of the material particle's impact $v_{3}$, which decreases by $d_{2}<0.5 \mathrm{~m}$, and it results in a decrease in kinetic energy of the material particle after the impact. Conversely, the velocity of material particle reflection $v_{3}$ and kinetic energy of material particle at the moment of impact increases by $d_{2}>0.5 \mathrm{~m}$. With regard to $d_{2}$ and vertical distance $y_{2}$, which the material particle has at the moment of impact on the damping plate, engineers and operators can determine the height of the DP.

The lowest instantaneous engine power of OC is achieved if the material particle, after rebound from the perpendicularly placed DP, falls onto the $\mathrm{OC}$ in a vertical direction, i.e. $\varphi_{2^{\prime}}=0^{\circ}$. This recommendation is applicable to all standard velocities of conveyor belts.

All the same, it is necessary to consider to what extent there is an increase in the value $d_{\mathrm{okr}}$ from a practical point of view, i.e. that with regard to the vertical distance between conveyors $d_{\text {dop }}$ it does not create a convergence of material particle to the DP after its separation from the drive pulley of IC. Tables 4 and 5 present change of the total height of shifting $d_{3}$ with regard to $d_{\mathrm{okr}}$ for both velocities.

Globally, in order to achieve a lower energy intensity of OC, a lower velocity of IC should be selected with a larger radius of the drive pulley along with the highest allowable distance of DP from the IC in the conveying system with material shifting from IC to the OC by application of DP; in addition, to achieve a lower total height of material shifting between IC and OC, it is suitable to choose a higher velocity 
Table 4. Change in rebound height $d_{3}$ with regard to $d_{\text {okr }}$ by $\mathrm{v}_{1}=2 \mathrm{~m} \mathrm{~s}^{-1}$.

\begin{tabular}{lllllll}
\hline \multirow{2}{*}{$R[\mathrm{~m}]$} & \multicolumn{5}{c}{ Change in the total height of rebound $d_{3}$ with regard to $d_{\mathrm{okr}}[\mathrm{m}]$} \\
\cline { 2 - 7 } & $d_{\mathrm{okr}}=0.5$ & $d_{\mathrm{okr}}=0.6$ & $d_{\mathrm{okr}}=0.7$ & $d_{\mathrm{okr}}=0.8$ & $d_{\mathrm{okr}}=0.9$ & $d_{\mathrm{okr}}=1$ \\
\hline 0.0500 & 0.87 & 1.02 & 1.19 & 1.39 & 1.61 & 1.85 \\
0.0625 & 0.89 & 1.04 & 1.21 & 1.41 & 1.64 & 1.88 \\
0.0800 & 0.91 & 1.07 & 1.25 & 1.45 & 1.68 & 1.93 \\
0.1000 & 0.94 & 1.10 & 1.28 & 1.49 & 1.73 & 1.98 \\
0.1250 & 0.98 & 1.14 & 1.33 & 1.55 & 1.79 & 2.05 \\
0.1575 & 1.03 & 1.20 & 1.40 & 1.62 & 1.87 & 2.14 \\
0.2000 & 1.10 & 1.28 & 1.49 & 1.73 & 1.98 & 2.27 \\
0.2500 & 1.19 & 1.39 & 1.61 & 1.85 & 2.12 & 2.42 \\
0.3150 & 1.31 & 1.53 & 1.76 & 2.02 & 2.31 & 2.62 \\
0.4000 & 1.49 & 1.73 & 1.98 & 2.27 & 2.57 & 2.90 \\
0.5000 & 2.03 & 2.38 & 2.77 & 3.19 & 3.65 & 4.15 \\
\hline
\end{tabular}

Table 5. Change in rebound height $d_{3}$ with regard to $d_{\text {okr }}$ by $\mathrm{v}_{1}=4 \mathrm{~m} \mathrm{~s}^{-1}$.

\begin{tabular}{lllllll}
\hline \multirow{2}{*}{$R[\mathrm{~m}]$} & \multicolumn{5}{c}{ Change in the total height of rebound $d_{3}$ with regard to $d_{\mathrm{okr}}[\mathrm{m}]$} \\
\cline { 2 - 7 } & $d_{\mathrm{okr}}=0.5$ & $d_{\mathrm{okr}}=0.6$ & $d_{\mathrm{okr}}=0.7$ & $d_{\mathrm{okr}}=0.8$ & $d_{\mathrm{okr}}=0.9$ & $d_{\mathrm{okr}}=1$ \\
\hline 0.0500 & 0.59 & 0.63 & 0.67 & 0.72 & 0.78 & 0.84 \\
0.0625 & 0.60 & 0.63 & 0.68 & 0.73 & 0.78 & 0.85 \\
0.0800 & 0.60 & 0.64 & 0.69 & 0.74 & 0.79 & 0.86 \\
0.1000 & 0.61 & 0.65 & 0.70 & 0.75 & 0.81 & 0.87 \\
0.1250 & 0.62 & 0.66 & 0.71 & 0.76 & 0.82 & 0.89 \\
0.1575 & 0.63 & 0.68 & 0.73 & 0.78 & 0.84 & 0.91 \\
0.2000 & 0.65 & 0.70 & 0.75 & 0.81 & 0.87 & 0.94 \\
0.2500 & 0.67 & 0.72 & 0.78 & 0.84 & 0.91 & 0.98 \\
0.3150 & 0.70 & 0.76 & 0.82 & 0.88 & 0.95 & 1.03 \\
0.4000 & 0.75 & 0.81 & 0.87 & 0.94 & 1.02 & 1.10 \\
0.5000 & 0.81 & 0.87 & 0.94 & 1.02 & 1.10 & 1.19 \\
\hline
\end{tabular}

of IC with a smaller radius of drive pulley and the lowest allowable DP distance from IC.

\section{Conclusions}

Belt conveying has an unsubstitutable place in many technological processes of the mining and processing industry. There is a constant need for its continuous improvement, including questions relating to construction and, in turn, the design of new or improved types of conveyor belts. Major attention should be paid to the places of movement where the material is transported off the conveyor belt. It is at this place where serious situations can occur which result in belt degradation or complete breakdown. The most frequent situations are a conveyor belt breakdown and high wear. In order to increase the effectivity of belt conveying, much attention should be paid to construction solution of shifting places in order to minimize the occurrence of serious situations resulting in conveyor belt breakdown. This, of course, is not the only way to deal with this. The other issue to be considered is the direction and orientation of material impact.

The direction and orientation of material impact have a direct influence on the conveyor's energy intensity. For the effective operation of conveyor belts, attention must be paid to the construction of the place of impact, especially in OC.

Acknowledgements. This work is a part of projects VEGA 1/0258/14, VEGA 1/0063/16, and KEGA 014STU-4/2015.

Edited by: A. Konuralp

Reviewed by: M. Pakdemirli and D. Ilic

\section{References}

Alspaugh, M. A.: Latest Developments in Belt Conveyor Technology, in MINExpo 2004, p. 11, Las Vegas, NV, USA, available at: http://www.overlandconveyor.com/pdf/ (last access: August 2016) 2004. 
Benjamin, B. C., Donecker, P., Huque, S., and Rozentals, J.: The Transfer Chute Design Manual For Conveyor Belt Systems, Aust. Bulk Handl. Rev., 1-8, 2010.

Bertrand, F., Leclaire, L. A., and Levecque, G.: DEM-based models for the mixing of granular materials, Chem. Eng. Sci., 60, 2517 2531, doi:10.1016/j.ces.2004.11.048, 2005.

Bierwisch, C., Kraft, T., Riedel, H., and Moseler, M.: Threedimensional discrete element models for the granular statics and dynamics of powders in cavity filling, J. Mech. Phys. Solids, 57, 10-31, doi:10.1016/j.jmps.2008.10.006, 2009.

CEMA: Belt conveyors for bulk materials, sixth ed., Conveyor Equipment Manufacturers Association, Naples, Florida, USA, 1600, 2007.

Chandramohan, R. and Powell, M. S.: Measurement of particle interaction properties for incorporation in the discrete element method simulation, Miner. Eng., 18, 1142-1151, doi:10.1016/j.mineng.2005.06.004, 2005.

David, J. and Kruses, P. E.: Conveyor Belt Transfer Chute Modeling and Other Applications using The Discrete Element Method in the Material Handling Industry, available at: http://www.ckit.co.za/secure/conveyor/papers/troughed/ conveyor/conveyor.htm, last access: August 2016.

Dewicki, G.: Bulk Material Handling and Processing - Numerical Techniques and Simulation of Granular Material, Bulk Solids Handl., 23, 2-5, 2003.

Di Renzo, A. and Di Maio, F. P.: Comparison of contactforce models for the simulation of collisions in DEMbased granular flow codes, Chem. Eng. Sci., 59, 525-541, doi:10.1016/j.ces.2003.09.037, 2004

Donohue, T. J., Roberts, A. W., Wheeler, C. A., and McBride, W.: Computer Simulations as a Tool for Investigating Dust Generation in Bulk Solids Handling Operations, Part. Part. Syst. Charact., 26, 265-274, 2010.

Grima, A. P. and Wypych, P. W.: Development and validation of calibration methods for discrete element modelling, Granul. Matter, 13, 127-132, doi:10.1007/s10035-010-0197-4, 2010.

Grima, A. P. and Wypych, P. W.: Discrete element simulations of granular pile formation: Method for calibrating discrete element models, Eng. Comput., 28, 314-339, doi:10.1108/02644401111118169, 2011.

Gröger, T. and Katterfeld, A.: Application of the Discrete Element Method in Materials Handling - Part 3: Transfer Stations, Bulk Solids Handl., 27, 158-167, 2007.

Hastie, D. B. and Wypych, P. W.: Experimental validation of particle flow through conveyor transfer hoods via continuum and discrete element methods, Mech. Mater., 42, 383-394, doi:10.1016/j.mechmat.2009.11.007, 2010.

Hou, Y. and Meng, Q.: Dynamic characteristics of conveyor belts, J. China Univ. Min. Technol., 18, 629-633, doi:10.1016/S10061266(08)60307-7, 2008.

Huque, A. G. and McLean, S. T.: Methods to predict material trajectories from belt conveyors and impact plates Part 1: Review, Bulk Solids Handl., 22, 348-354, 2002.
Jensen, R. P., Bosscher, P. J., Plesha, M. E., and Edil, T. B.: DEM simulation of granular media-structure interface: effects of surface roughness and particle shape, Int. J. Numer. Anal. Methods Geomech., 23, 531-547, 1999.

Kessler, F. and Prenner, M.: DEM - Simulation of Conveyor Transfer Chutes, FME Trans., 37, 185-192, 2009.

Mazurkiewicz, D.: Analysis of the ageing impact on the strength of the adhesive sealed joints of conveyor belts, J. Mater. Process. Technol., 208, 477-485, 2008.

McIlvenna, P. and Mossad, R.: Two Dimensional Transfer Chute Analysis Using a Continuum Method, in: Third International Conference on CFD in the Minerals and Process Industries CSIRO, 547-552, Melbourne, Australia, available at: available at: http://www.cfd.com.au/cfd_conf03/papers/064Mci.pdf (last access: August 2016), 2003.

Minkin, A.: Analysis of transfer stations of belt conveyors with help of discrete element method (DEM) in the mining industry, Transp. Logist., 12, 1-6, 2012.

Roberts, A. W.: Chute Performance and Design for Rapid Flow Conditions, Chem. Eng. Technol., 26, 163-170, doi:10.1002/ceat.200390024, 2003.

Roberts, A. W.: Chute Design Considerations for Feeding and Transfer, available at: http://login. totalweblite.com/Clients/doublearrow/beltcon2001/3. chutedesignconsiderationsforfeedingandtransfer.pdf (last acces: August 2016), unpublished data.

Scott, O. J.: Chute Design Considerations for Feeding and Transfer, in Conveyor Transfer Chute Design in Modern Concepts in Belt Conveying and Handling Bulk Solids, The Institute for Bulk Materials Handling Research, University of Newcastle, 809-820, 1992.

Scott, O. J. and Choules, P. R.: The use of impact plates in conveyor transfers, Tribol. Int., 26, 353-359, doi:10.1016/0301679X(93)90072-9, 1993.

Seifried, R., Schiehlen, W., and Eberhard, P.: Numerical and experimental evaluation of the coeffcient of restitution for repeted imacts, Int. J. Impact Eng., 32, 508-524, 2005.

Spaans, C.: The calculation of the main resistence of belt conveyors, Bulk Solids Handl., 11, 1999.

Wensrich, C. M.: Evolutionary optimisation in chute design, Powder Technol., 138, 118-123, doi:10.1016/j.powtec.2003.08.062, 2003.

Wensrich, C. M. and Wheeler, C. A.: Evolutionary optimisation in loading chute design, in: 8th International Conference on bulk materials storage, handling and transportation, University of Wollongong, Australia, 2004.

Zhang, S. and Xia, X.: A New Energy Calculation Model of Belt Conveyor, in AFRICON, 2009, 1-6, Nairobi, available at: http://timetable.cput.ac.za/_other_web_files/_cue/ICUE/ 2009/PPT/Presentation-XiaX.pdf, 2009.

Zhang, S. and Xia, X.: Modeling and energy efficiency optimization of belt conveyors, Appl. Energy, 88, 3061-3071, 2011. 